Research Article

\title{
Colorimetric Detection of Class A Soybean Saponins by G-Quadruplex-Based Hybridization Chain Reaction
}

\author{
Congcong Yin, ${ }^{1}$ Qiaoling Zhao, ${ }^{1}$ Aiqin Yue, ${ }^{2}$ Weijun Du, ${ }^{2}$ Dingbin Liu $\left(\mathbb{D},{ }^{3}\right.$ \\ Jinzhong Zhao $\mathbb{O}^{1},{ }^{1}$ Yongpo Zhang, ${ }^{1}$ and Min Wang ${ }^{2}$ \\ ${ }^{1}$ College of Arts and Sciences, Shanxi Agricultural University, Taigu 030801, Shanxi, China \\ ${ }^{2}$ College of Agronomy, Shanxi Agricultural University, Taigu 030801, Shanxi, China \\ ${ }^{3}$ College of Chemistry, Nankai University, Tianjin 300071, China
}

Correspondence should be addressed to Jinzhong Zhao; zhaojz@sxau.edu.cn

Received 9 August 2020; Revised 15 October 2020; Accepted 22 October 2020; Published 5 November 2020

Academic Editor: Ilari Filponnen

Copyright $(92020$ Congcong Yin et al. This is an open access article distributed under the Creative Commons Attribution License, which permits unrestricted use, distribution, and reproduction in any medium, provided the original work is properly cited.

Soybean saponin is one of the important secondary metabolites in seeds, which has various beneficial physiological functions to human health. GmSg-1 gene is the key enzyme gene for synthesizing class A saponins. It is of great significance to realize the visual and rapid detection of class A saponins at the genetic level. The hybridization chain reaction (HCR) was employed to the visual detection of $\mathrm{GmSg-1}$ gene, which was implemented by changing the length of the target fragment to $92 \mathrm{bp}$ and using the hairpin probes we designed to detect the $\mathrm{GmSg}-1^{a}$ and $\mathrm{GmSg}-1^{b}$ genes. The best condition of HCR reaction is hemin (1.2 $\left.\mu \mathrm{M}\right)$, Triton X-100 $(0.002 \%)$, ABTS $(3.8 \mu \mathrm{M})$, and $\mathrm{H}_{2} \mathrm{O}_{2}(1.5 \mathrm{mM})$. It was found that HCR has high specificity for $\mathrm{GmSg}-1$ gene and could be applied to the visual detection of different soybean cultivars containing Aa type, Ab type, and Aa/Ab type saponins, which could provide technical reference and theoretical basis for molecular breeding of soybean and development of functional soybean products.

\section{Introduction}

Soybean not only contains high-quality nutrients such as protein, oil, vitamin, and dietary fiber but also contains bioactive substances such as soybean saponin, soybean isoflavone, soybean phospholipid, and anthocyanin, which are beneficial to human health. As the main secondary metabolites in soybean seed, soybean saponins have become a research hotspot. Medical research has proved that soybean has many physiological functions, such as significantly reducing blood lipid, antiatherosclerosis, antioxidation, and antitumor and could be developed into health foods or medicines [1, 2]. However, it is difficult to separate, purify, and detect saponins because of their various types and complex structures. At present, the direct detection methods of soybean saponin mainly include thin-layer chromography (TLC) [3], aglycone colorimetry [4], high-performance liquid chromatography (HPLC) [5, 6], high-speed countercurrent chromatography (HSCCC) [7], and high- performance liquid chromatography-electrospray ionization-tandern mass spectrometry [8]. It is worth noting that each of these methods has its own shortcomings. For example, TLC can quickly screen and detect the content and composition of soybean saponins, but the results are not accurate enough; aglycone colorimetry cannot determine the content of total saponins; HPLC-MS needs corresponding standards, and the cost of operation is high. Therefore, it has become an urgent need to develop a simple and accurate method for qualitative and quantitative detection of soybean saponins. In recent years, the visual detection of DNA technology has attracted the attention of researchers because of its intuitive and rapid detection of genes [9]. Moreover, due to the advantages of simple, rapid, and sensitive and without the participation of natural enzymes, great efforts have been made in exploring the potential application of colorimetric assays in scientific research and clinical diagnosis, for example, detection of small-molecular antibiotic residues, quantitative screening of small-molecular mycotoxins, enzyme- 
free sensitive detection of alpha-fetoprotein (AFP), and so on [10-14].

As an important achievement in the development of modern molecular biology, genetic analysis has been widely used in the detection and identification of substances and could also be used as a reliable method for identification of class A saponins. In order to get more tested products in the shortest time to improve the sensitivity of detection, the majority of target genes are amplified by PCR; thus the detection of target genes could be transformed into the detection of PCR products for electrophoresis observation. However, this detection method is prone to false-positive results and requires complicated manipulations. In 2004, the hybridization chain reaction (HCR) proposed by Dirks and Pierce [15] is an enzyme-independent nucleic acid detection technology, which can realize the detection of nucleic acids at room temperature with only one pair of hairpin DNA probes. Compared with proteases, DNA probes are cheap, stable, and easy to store; compared with PCR and other amplification technologies, HCR could be completed at room temperature without strict reaction conditions and special equipment. These advantages are of great significance to simplify operation and make HCR system an ideal platform for developing nucleic and detection based on visual chip. Due to its advantages such as high-efficiency, isothermal amplification, ultra-high sensitivity, structural versatility, and enzyme-free properties, HCR has become a powerful molecular biology tool with wide application prospects in the fields of biosensing, bioimaging and biomedicine [16-18]. Thus far, HCR has been used for sensitive detection of various targets, including nucleic acids (DNA and RNA) [19], proteins [20, 21], enzyme activities [22], small biomolecules [23-25], metal ions [26, 27], and even tumor cells $[28,29]$. Dong et al. [30] found that the gene polymorphism could be detected via the integration of HCR and G-quadruplex; the G-quadruplex released by HCR could combine with hemin chloride and color development, thus achieving target gene detection. This method has the advantages of high sensitivity, fast speed, and simplicity. However, it has not been reported to be applied to the identification of class A soybean saponins. GmSg-1 gene is the key enzyme gene for synthesizing class A saponins. $G m S g-1$ gene is subdivided into $G m S g-1^{a}$ and $G m S g-1^{b}$. $G m S g-1^{a}$ gene encodes xylose transferase, which connects xylose at the C-22 terminal of saponin Aa, while $\mathrm{GmSg-1}{ }^{b}$ gene encodes glucosyltransferase where glucose is conjugated to the C-22 terminal of saponin Ab. Studies have found that glycosylation occurs at C-22 and C-3 positions on daidzein. The key enzymes regulating the synthesis of saponins $\mathrm{Aa}$ and $\mathrm{Ab}$, xylosyltransferase (UGT73F4), and glucosytransferase (UGT73F2) are encoded by two alleles of $G m S g-1^{a}$ and $G m S g-1^{b}$ [31]. In this study, we applied the integration of HCR and G-quadruplex to identify the two key enzyme genes. The purpose is to explore the feasibility of visual qualitative analysis of soybean saponins by HCR, which is of great significance for the identification of class A saponins in soybean germplasm resources, and provides a basis for molecular breeding of soybean and development of functional soybean products.

\section{Experimental Section}

2.1. Materials and Reagents. Hemin, $\mathrm{ABTS}$, and $\mathrm{H}_{2} \mathrm{O}_{2}$ were purchased from Aladdin (Shanghai, China). Lambda exonuclease was purchased from Fermentas. Taq DNA polymerase, Taq buffer, and dNTP were purchased from Beijing TransGen Biotech Co., Ltd. (Beijing, China). All DNA sequences (Table 1, Supporting information) were synthesized and PAGE purified by Shanghai Sangon Biological Engineering Technology and Services (Shanghai, China). Tris, Triton $\mathrm{X}-100, \mathrm{NaCl}, \mathrm{KCl}, \mathrm{HCl}$, and $\mathrm{NaOH}$ were purchased from Heowns. Pipettes, microplate readers, and PCR amplifiers were purchased from Eppendorf. Canon camera was made by Canon. Gel imager was made by Shanghai Jiapeng Technology. Ball mill was made by Guobang mining machinery. All the solutions were prepared with sterile ultrapure water.

2.2. Instruments. PCR (Eppendorf AG), electrophoresis (Bio-RAD powerpac Basic), nuclear acid analyzer (Eppendorf Kinetic), gel imaging system (BIO-GENER GT9612), freeze dryer (Hetopowerdry), cryogenic refrigerator (Haier), and electronic balance (Shimadzu).

2.3. DNAzyme-Based PCR Amplification. The PCR was carried out in a mixture containing $4.2 \mu \mathrm{L}$ DNA template $(20 \mathrm{ng} / \mu \mathrm{L}), 3.0 \mu \mathrm{L}$ Taq buffer $(10 \times), 0.6 \mu \mathrm{L}$ primer1 (TA92F, $10 \mu \mathrm{M}$ ) and $0.6 \mu \mathrm{L}$ primer2 (TA92R, $10 \mu \mathrm{M}$ ); $2.4 \mu \mathrm{L}$ dNTP $(2.5 \mu \mathrm{M}), 0.6 \mu \mathrm{L}$ Taq DNA polymerase, and $0.6 \mu \mathrm{L}$ sterile water were added to make a final volume $30 \mu \mathrm{L}$. The PCR procedure was as follows: $95^{\circ} \mathrm{C}$ for $5 \mathrm{~min} ; 95^{\circ} \mathrm{C} 1 \mathrm{~min}, 6^{\circ} \mathrm{C}$ $45 \mathrm{~s}, 72^{\circ} \mathrm{C}$ for $8 \mathrm{~s}, 35$ cycles; and $72^{\circ} \mathrm{C}$ for $10 \mathrm{~min}$. The target sequence of $92 \mathrm{bp}$ was obtained and detected by $3 \%$ agarose gel electrophoresis.

To obtain single-stranded target fragments required for $\mathrm{HCR}$, an enzyme digestion reaction was performed: $1 \mu \mathrm{L}$ lambda exonuclease was added to $19 \mu \mathrm{L}$ PCR products, $37^{\circ} \mathrm{C}$, $90 \mathrm{~min}$ and $85^{\circ} \mathrm{C}, 15 \mathrm{~min}$. The digested products were detected by $3 \%$ agarose gel electrophoresis.

2.4. Colorimetric Detection. The hairpins probes need to be pretreated as follows: GA1 $(1.5 \mu \mathrm{L}, 10 \mu \mathrm{M})$ and GA2 $(1.5 \mu \mathrm{L}$, $10 \mu \mathrm{M})$ were mixed with $5 \times$ Tris/HCl-Na buffer $(2.0 \mu \mathrm{L}$, Tris $100 \mathrm{mM}, \mathrm{NaCl} 2 \mathrm{M}, \mathrm{pH}$ 7.2), respectively, and then heated to $95^{\circ} \mathrm{C}$ for $5 \mathrm{~min}$ and cooled down to ambient temperature for $1 \mathrm{~h}$ before use.

The total volume of HCR system was $10 \mu \mathrm{L}$, containing enzyme digestion product $(8 \mu \mathrm{L})$, the pretreated probes GA1 $(0.5 \mu \mathrm{L})$ and GA2 $(0.5 \mu \mathrm{L})$, and $0.5 \mu \mathrm{L} \mathrm{HCl}-\mathrm{NaCl}$ $(0.04 \mathrm{M} \mathrm{HCl}, 4 \mathrm{M} \mathrm{NaCl})$ to maintain the $\mathrm{pH}$ of the reaction system. The reaction was performed for $1 \mathrm{~h}$ at $37^{\circ} \mathrm{C}$ and then terminated on ice. After that, $\mathrm{KCl}(0.135 \mu \mathrm{M})$, hemin $(1.2 \mu \mathrm{M})$, and Triton X-100 $(0.002 \%)$ were added into the reaction mixture, and then followed by the addition of ABTS $(3.8 \mathrm{mM})$ and $\mathrm{H}_{2} \mathrm{O}_{2}(1.5 \mathrm{mM})$, the color changes were observed at about $10 \mathrm{~min}$, and the results were detected by $3 \%$ agarose gel electrophoresis. By using this 


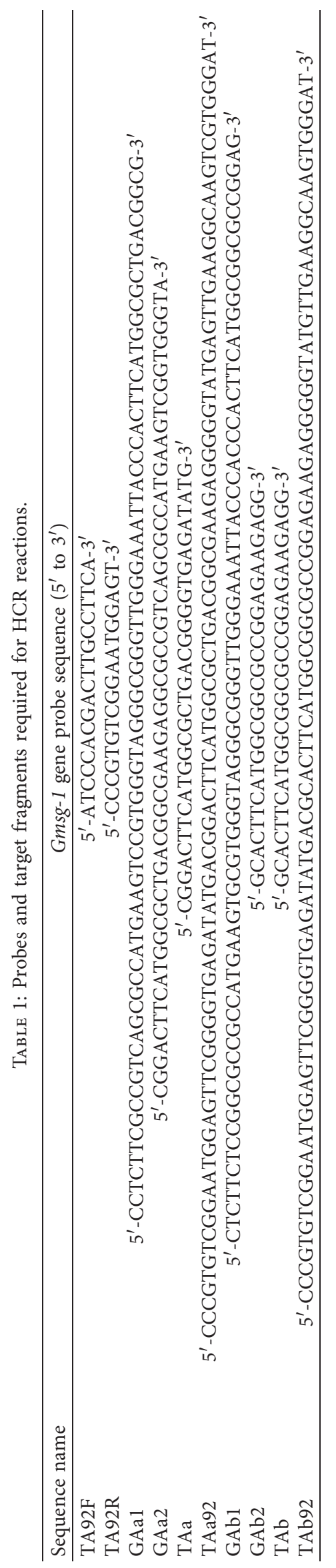


method, six soybean cultivars, Wuhei, Jinda 73 , Jinyi 30 , Jinke 4, WS285, and Jinda 47, were detected with two pairs of probes GAa1/GAa2 and GAb1/GAb2, respectively.

2.5. Visual-Chip-Based Assay of GmSg-1. The visual-chip carrier was made by a thick transparent plastic sheet which was washed thoroughly and sterilized with alcohol. Six gene chips were fixed in two rows on the plastic sheet, three in each row, each circle with a diameter of $0.8 \mathrm{~cm}$. The pretreated probes GAa1/GAa2 and GAb1/GAb2 were mixed with $5 \times$ Tris/HCl-Na buffer (Tris $100 \mathrm{mM}, \mathrm{NaCl} 2 \mathrm{M}$, pH 7.2), respectively; $3 \mu \mathrm{L}$ each of the solution was taken and mixed completely. Then the mixed solution was pipetted onto the chip and dried at $37^{\circ} \mathrm{C}$ to obtain the visual chip ready for target detection. Target fragment TAa $(0.1 \mu \mathrm{L}$, $10 \mu \mathrm{M})$ and target fragment $\operatorname{TAb}(0.1 \mu \mathrm{L}, 10 \mu \mathrm{M})$ were pipetted into the upper and lower circle on the visual chip, respectively. The blank circles were printed on sterile ultrapure water $(0.1 \mu \mathrm{L})$ instead of target fragment. The reaction was also carried out at $37^{\circ} \mathrm{C}$ for $1 \mathrm{~h}$. After that, $\mathrm{KCl}$ $(0.135 \mu \mathrm{M})$, hemin $(1.2 \mu \mathrm{M})$, and Triton X-100 $(0.002 \%)$ were pipetted onto the chip; two minutes later, ABTS $(3.8 \mathrm{mM})$, $\mathrm{H}_{2} \mathrm{O}_{2}(1.5 \mathrm{mM})$ was added in the drops and color differences were observed.

\section{Results and Discussion}

3.1. The Principle of DNAzyme-Based HCR Assays for GmSg-1 Genes. The principle of GmSg-1 gene detection based on HCR is illustrated in Scheme 1. To implement our strategy, we designed the sequences (TF, TR, 92 bp) of targeted $\mathrm{GmSg}-1 \mathrm{a}$ and $\mathrm{GmSg}-1^{b}$, and two pairs of complementary specific hairpin probes GAal/GAa2 and GAb1/GAb2 according to the target recognition region (the sequences are shown in Table 1). Complementary sequences are marked by the same number with or without a single quote ('). The punctuation () indicates that there is only one base difference. In the hairpin probe GA1, the sequence of $1^{\prime}-2^{\prime}$ is complementary to the $1-2$ of the target sequence $\mathrm{T}, 3-4$ is G-quadruplex fragment with two-thirds locked in the loop. In the hairpin probe GA2, the sequence of 1-2 is identical with the 1-2 of the target sequence $\mathrm{T}$.

Firstly, the 5'-phosphorylated strand of duplex DNA was amplified by PCR before hybridization chain reaction; the PCR products were digested by Lambda Exonuclease that could specifically recognize and cleave the $5^{\prime}$-terminal phosphorylated DNA polymers; thus the double-stranded DNA could be turned into a single strand. When the target fragment is absent in the reaction system, the structures of pretreated probes GA1 and GA2 are metastable and the G-quadruplex is blocked in the hairpin structure and has no activity. However, when the target fragment is present, a cascade amplification reaction could be proceeded. Because $1^{\prime}-2^{\prime}$ of probe GA1 is completely complementary to $1-2$ of the target sequence $\mathrm{T}$, the probe GA1 could be opened to release the G-quadruplex 3-4 and the sequence $3^{\prime}-2$ that can trigger the probe GA2 to open. After the probe GA2 is opened, the same sequence 1-2 can play the same role as the target fragment. In this way, GA2 and GA1 are opened successively; the result is that the formation of long-stranded DNA polymeric molecules and DNA polymers bearing lots of G-quadruplex in between are produced. The G-quadruplex combined with hemin has catalase activity that can catalyze the oxidation of ABTS by $\mathrm{H}_{2} \mathrm{O}_{2}$, turning it into green $\mathrm{ABTS}^{+}$. The results could be observed directly or determined by spectrophotometer at $420 \mathrm{~nm}$.

3.2. Validation of the HCR Assay for GmSg-1 Genes. To demonstrate the feasibility of the detection method for $G m S g-1$ gene, three pairs of pretreated hairpin probes GAa1 $(1.5 \mu \mathrm{L}, 10 \mu \mathrm{M})$ and GAa2 $(1.5 \mu \mathrm{L}, 10 \mu \mathrm{M})$ were added into target sequence TAa $(0.1 \mu \mathrm{L}, 10 \mu \mathrm{M})$, TAb $(0.1 \mu \mathrm{L}, 10 \mu \mathrm{M})$, and sterile ultrapure water $(0.1 \mu \mathrm{L})$, respectively. The treatment group that replaced the target sequence with sterile ultrapure water served as the blank group. Water was added to HCR system to make a final volume of $20 \mu \mathrm{L}$. The same treatment was done for hairpin probes GAbl and GAb2. After the completion of hybridization chain reaction, color reaction was carried out as described in 2.4 , and then the experimental results were recorded by taking photos and $3 \%$ agarose gel electrophoresis. The results showed that, in the presence of target gene TAa, the assay solution of HCR containing probes GAa1 and GAa2 turned green rapidly (Figure 1(a)) and the corresponding electrophoresis results (Figure 1(b)) showed that HCR occurred and yielded a set of long-chain polymers with different molecular weights. However, when probes GAb1 and GAb2 were present, the assay solution remained colorless under the same conditions; the corresponding electrophoresis results showed that only the remaining probes were found, and no polymers with different molecular were produced. In parallel, when the target gene was replaced by TAb, the similar results were achieved with high specificity. The results demonstrate that HCR not only has the feasibility of the colorimetric assay but also has a strong ability to differentiating gene sequence, so it could be used to identify $\mathrm{GmSg}-1^{a}$ and $\mathrm{GmSg}-1^{b}$ in different soybean cultivars.

\subsection{Qualitative Detection of GmSg-1 Genes from Soybean} Cultivars. Based on the determination of soybean saponin content by HPLC-ESI-MS/MS, two soybean cultivars containing only Aa saponin (Wuhei and Jinda 73), two soybean cultivars containing only Ab saponin (Jinyi 30 and Jinke 4), and two soybean cultivars containing both Aa and Ab WS 285 and Jinda 47) were selected to detect $G m S g-1^{a}$ and $G m S g-1^{b}$ genes by HCR. According to the $\mathrm{GmSg}-1^{a}$ and $\mathrm{GmSg}-1^{b}$ gene sequences, universal primers were designed to determine the target fragment. The target fragment length that could be amplified was finally selected to be $92 \mathrm{bp}$ with the aid of NUPACK software. As seen from agarose gel analysis results (Figure 2(a)), stable double strands (TF/TR, $92 \mathrm{bp}$ ) were obtained by PCR amplification with the $\mathrm{GmSg}-1^{a}$ and $\mathrm{GmSg}-1^{b}$ sequences that were collected from the six cultivars mentioned above. With the aid of lambda exonuclease, the double strands were cleaved into single strands, which were also confirmed by the agarose gel analysis (Figure 2(b)). To perform the test, 


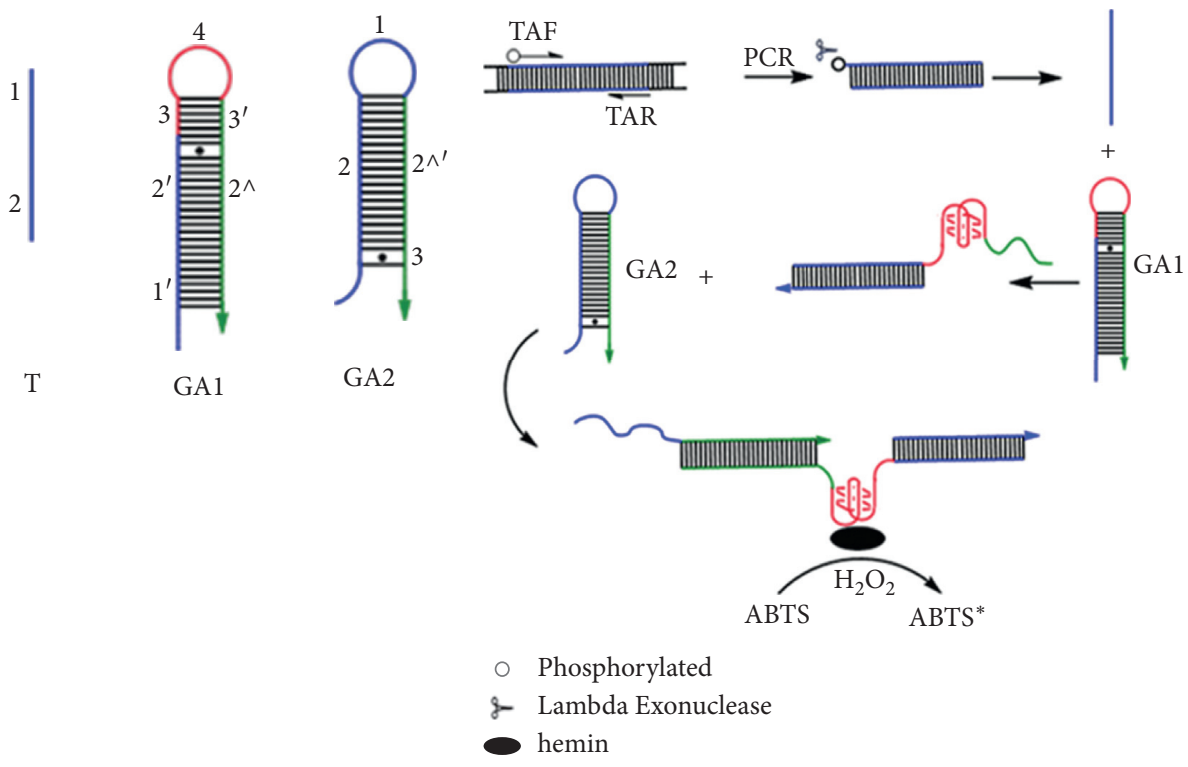

(a)

(b)

Scheme 1: Schematic diagram of hybridization chain reaction. (a)Target fragment and structure of hairpin probes. The target should be single-stranded DNA. Sequences marked with the same number with or without a single quote (') are complementary to each other, and the punctuation () indicates that there is only one base difference between them.(b) The process of detecting GmSg-1 by HCR reaction. In the absence of target, the structures of hairpin probes GA1 and GA2 are metastable and G-quadruplex is enclosed in the loop. Once the target is present, probes GA1 and GA2 are opened successively and hybridization chain reaction was generated, lots of G-quadruplex are released and combined with hemin to catalyze the oxidation of ABTS by $\mathrm{H}_{2} \mathrm{O}_{2}$ to green ABTS ${ }^{+}$.

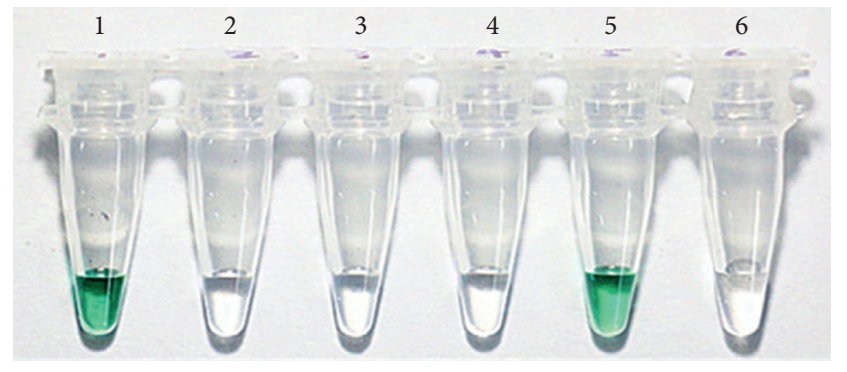

(a)

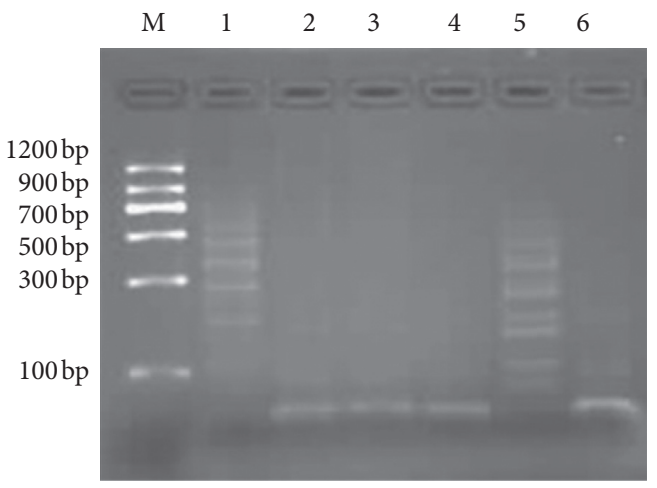

(b)

Figure 1: Colorimetric detection of the $G m S g-1^{a}$ and $G m S g-1^{b}$ using the HCR assays. (a) The photograph illustrates the colorimetric results of tubes $1-6$ by adding different hairpin probes and target genes. Tube 1: GAa1 + GAa2 + TAa. Tube 2: GAa1 + GAa2 + TAb. Tube 3: blank. Tube 4: GAb1 + GAb2 + TAa. Tube 5: GAb1 + GAb2 + TAb. Tube 6: blank. (b) The corresponding results of 3\% agarose gel electrophoresis.

hemin $(1.2 \mu \mathrm{M})$, Triton X-100 (0.002\%), ABTS $(3.8 \mathrm{mM})$, and $\mathrm{H}_{2} \mathrm{O}_{2}(1.5 \mathrm{mM})$ were added to the mixtures of hybridization chain reaction containing varied soybean cultivars. In the presence of probes GAa1 and GAa2, the color of solution containing GmSg-1a genes turned into green in $10 \mathrm{~min}$. In detail, tubes 1, 2, 5, and 6 containing Wuhei, Jinda 73, WS 285, and Jinda 47, respectively, showed obvious change from colorless to green (Figure 3 ). In contrast, tubes 3 and 4 containing Jinyi 30 and Jinke 4 remained colorless, demonstrating the specific expression of $\mathrm{GmSg}-1^{a}$ gene in these four soybean cultivars (Figure 3). Similarly, in the presence of probes of
GAb1 and GAb2, the colorless to green change was observed in tubes $9,10,11$, and 12 , and tubes 7 and 8 containing Wuhei and Jinda 73 remained colorless, indicating the specific expression of $G m S g-1^{b}$ gene in Jinyi 30, Jinke 4, WS 285, and Jinda 47 (Figure 3 ). The results of agarose gel analysis are consistent with those of colorimetric determination (Figures 2(c)-2(d)). For the cultivars Jinyi 30 and Jinke 4, no HCR products for the $\mathrm{GmSg-1}{ }^{a}$ sequences were detected in the assay mixture containing GAa1 and GAa2, while HCR products of $G m S g-1^{b}$ sequences were detected in the presence of GAb1 and GAb2. On the contrary, for the cultivars Wuhei and Jinda 73, HCR 


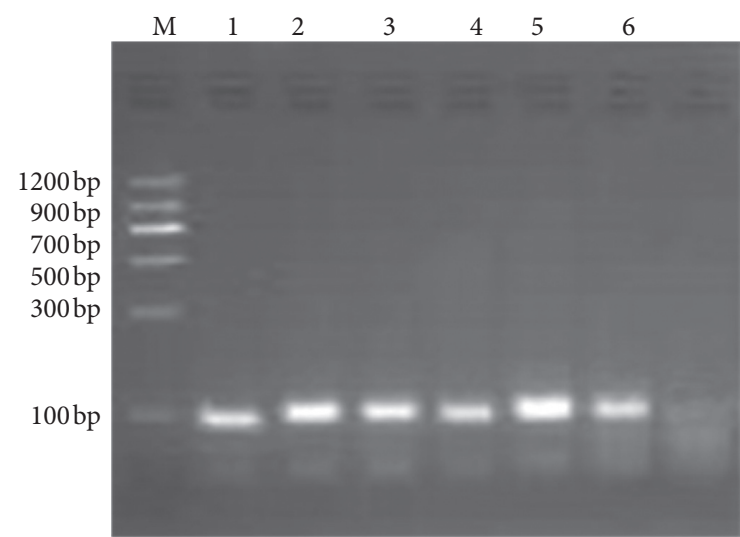

(a)

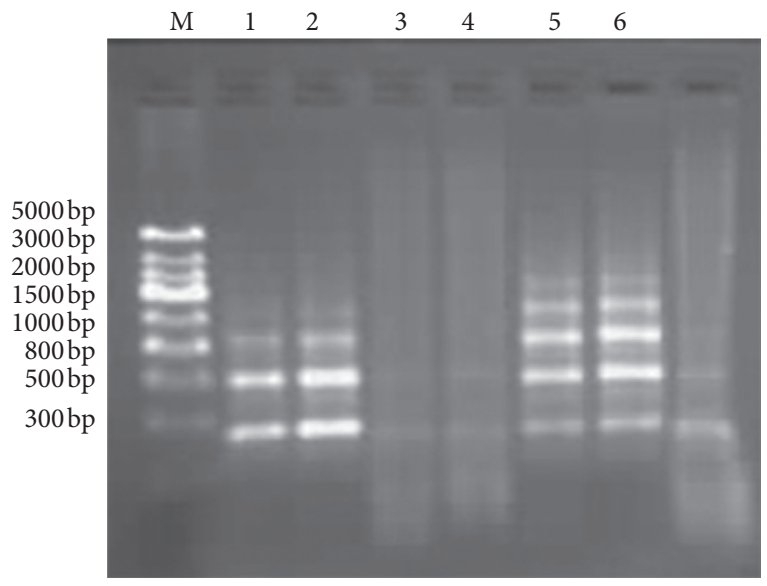

(c)

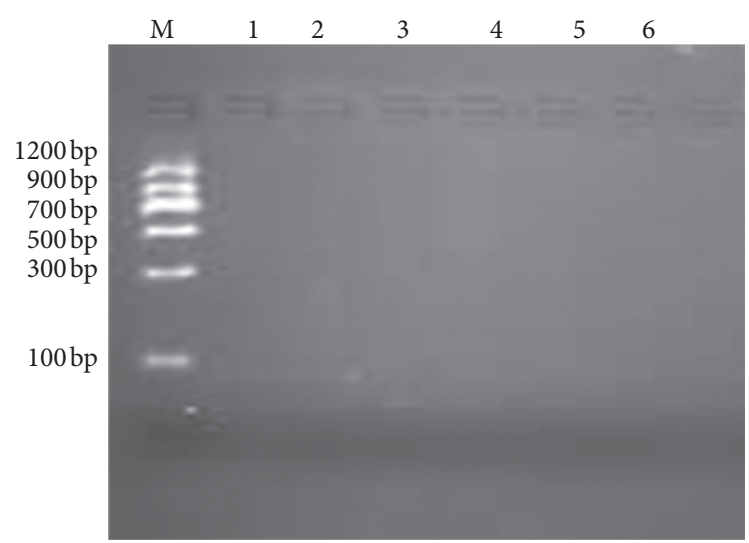

(b)

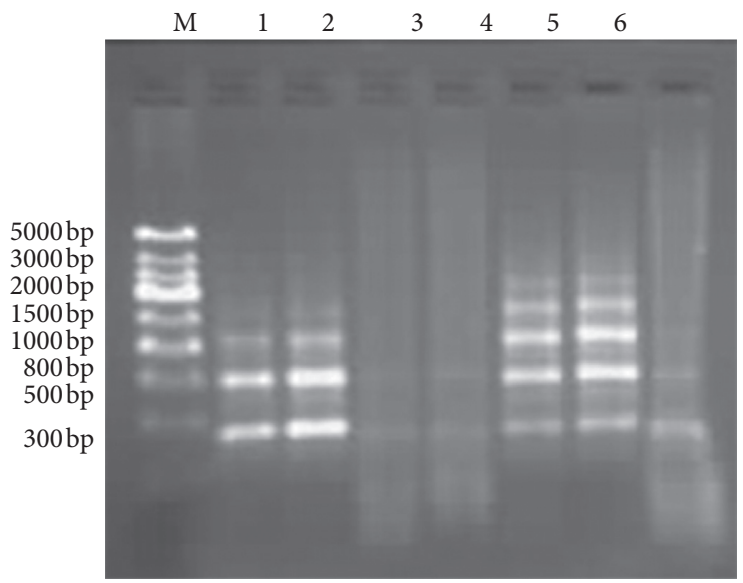

(d)

Figure 2: Electropherogram of target gene fragment in HCR. The lanes on both sides of the gel are DNA markers; lanes 1-6 represent six soybean cultivars in sequence: Wuhei, Jinda 73, Jinyi 30, Jinke 4, WS 285, and Jinda 47 in HCR system. (a) Double-strand target gene (TF/TR) amplified by PCR. (b) Agarose gel analysis of the PCR product digested by lambda exonuclease. (c) Agarose gel analysis of HCR products in the presence of probes GAa1 and GAa2. (d) Agarose gel analysis of HCR products in the presence of probes GAb1 and GAb2.

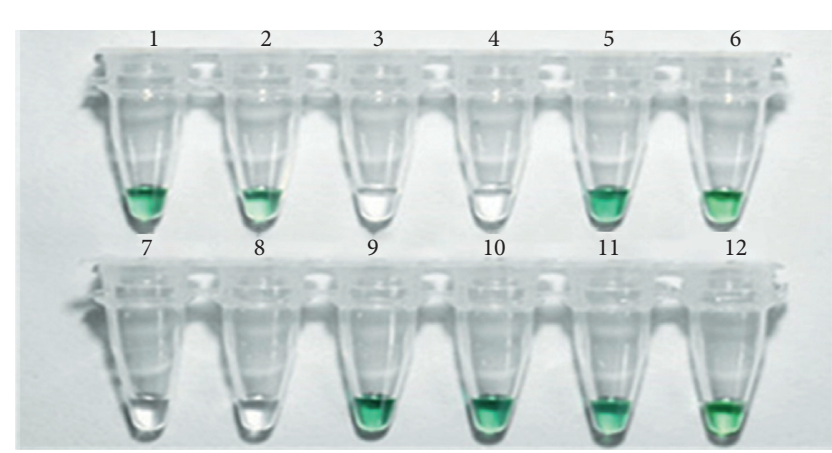

FIGURE 3: Colorimetric detection results for soybean $G m S g-1^{a} / G m S g-1^{b}$ genes. Photograph of HCR assay solutions containing hemin $(1.2 \mu \mathrm{M})$, Triton X-100 (0.002\%), ABTS $(3.8 \mu \mathrm{M}), \mathrm{H}_{2} \mathrm{O}_{2}(1.5 \mathrm{mM})$, and target genes $\mathrm{GmSg}-1^{a}$ and $\mathrm{GmSg}-1^{b}$ collected from different soybean cultivars. Tubes 1 , 7: Wuhei. Tubes 2, 8: Jinda 73. Tubes 3, 9: Jinyi 30. Tubes 4, 10: Jinke 4. Tubes 5, 11: WS 285. Tubes 6, 12: Jinda 47.

products of $G m S g-1^{a} \mathrm{G}$ sequence instead of $G m S g-1^{b}$ sequence were detected. For the cultivars WS 285 and Jinda 47, both $G m S g-1^{a}$ sequence and $G m S g-1^{b}$ sequence were detected.
Generally speaking, if the tested sample contains Aa saponin, the color of HCR system will change from colorless to green in the presence of probes GAa1 and GAa2, while it will remain colorless after adding probes GAb1 and GAb2; however, the tested sample containing $\mathrm{Ab}$ saponin is the opposite. Therefore, hybridization chain reaction can be used to detect $G m S g-1^{a}$ and $G m S g-1^{b}$.

3.4. Visual-Chip-Based Assay of GmSg-1 Genes. To facilitate the use of HCR system for detection, we tried to make a gene chip based on HCR system. The pretreated DNA probes GA1/GA2 and GAb1/GAb2, which were designed to detect the $G m S g-1^{a}$ and $G m S g-1^{b}$, mixed with $5 \times$ Tris-HCl buffer and then printed on a plastic sheet in advance, and then the hybridization chain reaction would be generated by pipetting the target genes TAa and TAb. The colorimetric assay of HCR could be performed on the sheet after adding the corresponding reagents of oxidation reaction, as shown in Figure 4 . The results are consistent with the specificity experiments; the circles which were printed GAa1/GAa2 and 


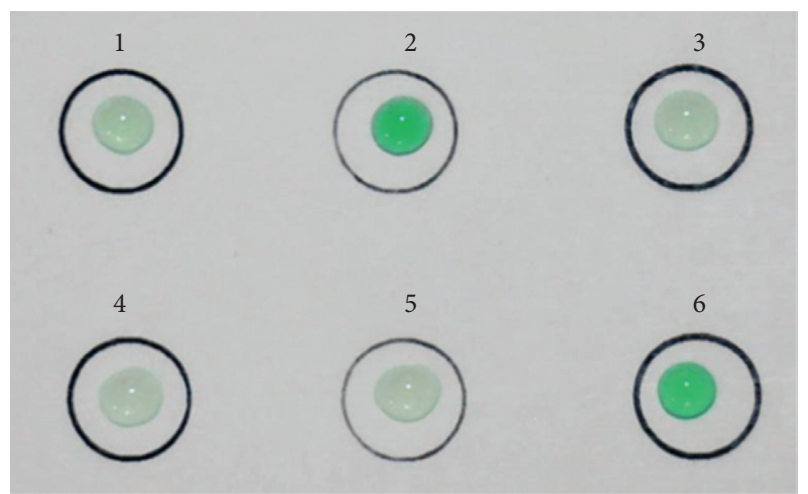

FIGURE 4: Visual-chip based detection of $G m S g-1$. Each circle was coated with a mixture of HCR systems containing different hairpin probes and target genes with different sequences. Circles 1 and 4: the probes in the system were replaced with sterile ultrapure water as blank; target genes were GAa1/GAa2 and GAb1/GAb2, respectively. Circles 2 and 3: the probes in the system were all GAa1/GAa2; the target genes were TAa and Tab, respectively. Circles 5 and 6: the probes in the system were all GAb1/GAb2; the target genes were TAa and Tab, respectively.

GAb1/GAb2 show green in the presence of corresponding genes TAa and $\mathrm{TAb}$, respectively. However, when the circles printed GAa1/GAa2 and GAb1/GAb2 were added to opposite target genes $\mathrm{TAb}$ and $\mathrm{TAa}$, the results are as colorless as the blank. Therefore, the HCR system can also be made into a gene chip for the detection of $G m S g-1^{a}$ and $\mathrm{GmSg}-1^{b}$.

\section{Conclusions}

In this study, we studied the feasibility of HCR system to identify class A soybean saponins by detecting their corresponding encoded $\mathrm{GmSg-1}$ genes. It was found that hybridization chain reaction has excellent specificity in detecting genes, and the results were confirmed by agarose gel (3\%) electrophoresis, so it could be used to identify the GmSg-1 in different soybean cultivars. Furthermore, a convenient visual chip based on hybridization chain reaction was made by printing the probes designed to $\mathrm{GmSg}$ 1 sequence on plastic sheet; the colorimetric assay could be implemented by the naked eye without resorting to expensive equipment, which has the advantages of high sensitivity, speed, and simplicity. In addition, the application of hybridization chain reaction on quantitative analysis of gene $\mathrm{GmSg}$-1 should be further studied.

\section{Data Availability}

The data used to support the findings of this study are included within the article.

\section{Conflicts of Interest}

There are no conflicts of interest to declare.

\section{Acknowledgments}

This work was financially supported by the Key R\&D Project of Shanxi (201903D211006-1,201703D221008-4, 201903D221036, 201703D211001, 201703D221004-5, and 201803D221020-2) and Award Research Projects for Excellent Doctors in Shanxi Province (SXYBKY201807).

\section{References}

[1] S.-O. Lee, A. L. Simons, P. A. Murphy, and S. Hendrich, "Soyasaponins lowered plasma cholesterol and increased fecal bile acids in female golden Syrian hamsters," Experimental Biology and Medicine, vol. 230, no. 7, pp. 472-478, 2005.

[2] A. A. Ellington, M. Berhow, and K. W. Singletary, "Induction of macroautophagy in human colon cancer cells by soybean B-group triterpenoid saponins," Carcinogenesis, vol. 26, no. 1, pp. 159-167, 2005.

[3] T. Yoshitake, S. Hiroko, S. Takashi et al., "Genetic and chemical analysis of a key biosynthetic step for soyasapogenol A, an aglycone of group A saponins that influence soymilk flavor," Theoretical and Applied Genetics, vol. 126, no. 3, pp. 721-731, 2013.

[4] S. Kudou, M. Tonomura, C. Tsukamoto, M. Shimoyamada, T. Uchida, and K. Okubo, "Isolation and structural elucidation of the major genuine soybean saponin," Bioscience, Biotechnology, and Biochemistry, vol. 56, no. 1, pp. 142-143, 1992.

[5] P. Krishnamurthy, C. Tsukamoto, S. H. Yang, J. D. Lee, and G. Chung, "An improved method to resolve plant saponins and sugars by TLC," Chromatographia, vol. 75, no. 23-24, pp. 1445-1449, 2012.

[6] J. Hu, S.-O. Lee, S. Hendrich, and P. A. Murphy, "Quantification of the group B soyasaponins by high-performance liquid chromatography," Journal of Agricultural and Food Chemistry, vol. 50, no. 9, pp. 2587-2594, 2002.

[7] J. Lin and C. Wang, "An analytical method for soy saponins by HPLC/ELSD," Journal of Food Science, vol. 69, no. 6, pp. C456-C462, 2004.

[8] K. Decroos, J.-P. Vincken, L. Heng, R. Bakker, H. Gruppen, and W. Verstraete, "Simultaneous quantification of differently glycosylated, acetylated, and 2,3-dihydro-2,5-dihydroxy-6methyl-4H-pyran-4-one-conjugated soyasaponins using reversed-phase high-performance liquid chromatography with evaporative light scattering detection," Journal of Chromatography A, vol. 1072, no. 2, pp. 185-193, 2005.

[9] Z. Gao, Z. Qiu, M. Lu, J. Shu, and D. Tang, "Hybridization chain reaction-based colorimetric aptasensor of adenosine $5^{\prime}$ triphosphate on unmodified gold nanoparticles and two labelfree hairpin probes," Biosensors and Bioelectronics, vol. 89, pp. 1006-1012, 2017.

[10] R. Ren, G. Cai, Z. Yu, Y. Zen, and D. Tang, "Metal-polydopamine framework: an innovative signal-generation tag for colorimetric immunoassay," Analytical Chemistry, vol. 90, no. 8, pp. 11099-11105, 2018.

[11] R. Ren, G. Cai, Z. Yu, Y. Zeng, and D. Tang, "Glucose-loaded liposomes for amplified colorimetric immunoassay of streptomycin based on enzyme-induced iron (II) chelation reaction with phenanthroline," Sensors and Actuators, B: Chemical, vol. 265, pp. 174-181, 2020.

[12] Z. Gao, M. Xu, L. Hou, G. Chen, and D. Tang, "Magnetic bead-based reverse colorimetric immunoassay strategy for sensing biomolecules," Analytical Chemistry, vol. 85, no. 14, pp. 6945-6952, 2013. 
[13] Z. Gao, D. Tang, D. Tang, R. Niessner, and D. Knopp, “Targetinduced nanocatalyst deactivation facilitated by Core@Shell nanostructures for signal-amplified headspace-colorimetric assay of dissolved hydrogen sulfide," Analytical Chemistry, vol. 87, no. 19, pp. 10153-10160, 2015.

[14] W. Lai, Q. Wei, M. Xu, J. Zhuang, and D. Tang, "Enzymecontrolled dissolution of $\mathrm{MnO}_{2}$ nanoflakes with enzyme cascade amplification for colorimetric immunoassay," Biosensors and Bioelectronics, vol. 89, pp. 645-651, 2017.

[15] T. Yoshitake, S. Takashi, K. Akio et al., "Genetic analysis of variation in sugar chain composition at the C-22 position of group A saponins in soybean, glycine max (L.) merrill," Breeding Science, vol. 60, no. 1, pp. 3-8, 2010.

[16] B. Zhang, B. Liu, D. Tang, R. Niessner, G. Chen, and D. Knopp, "DNA-based hybridization chain reaction for amplified bioelectronic signal and ultrasensitive detection of proteins," Analytical Chemistry, vol. 84, no. 12, pp. 5392-5399, 2012.

[17] K. Zhang, S. Lv, Q. Zhou, and D. Tang, "CoOOH nanosheetscoated g-C3N4/CuInS2 nanohybrids for photoelectrochemical biosensor of carcinoembryonic antigen coupling hybridization chain reaction with etching reaction," Sensors and Actuators B: Chemical, vol. 307, Article ID 127631, 2020.

[18] R. Zeng, L. Zhang, L. Su, Z. Luo, Q. Zhou, and D. Tang, "Photoelectrochemical bioanalysis of antibiotics on rGOBi2WO6-Au based on branched hybridization chain reaction," Biosensors and Bioelectronics, vol. 133, pp. 100-106, 2019.

[19] J. Ikbal, G. S. Lim, and Z. Gao, "The hybridization chain reaction in the development of ultrasensitive nucleic acid assays," Trac Trends in Analytical Chemistry, vol. 64, no. 1, pp. 86-99, 2015.

[20] J. Zhou, M. Xu, D. Tang, Z. Gao, J. Tang, and G. Chen, "Nanogold-based bio-bar codes for label-free immunosensing of proteins coupling with an in situ DNA-based hybridization chain reaction," Chemical Communications, vol. 48, no. 100, pp. 12207-12209, 2012.

[21] J. Xu, J. Wu, C. Zong, H. Ju, and F. Yan, "Manganese porphyrin-dsDNA complex: a mimicking enzyme for highly efficient bioanalysis," Analytical Chemistry, vol. 85, no. 6, pp. 3374-3379, 2013.

[22] S. Bi, T. Zhao, B. Luo, and J.-J. Zhu, "Hybridization chain reaction-based branched rolling circle amplification for chemiluminescence detection of DNA methylation," Chemical Communications, vol. 49, no. 61, pp. 6906-6908, 2013.

[23] J. Ge, Z.-M. Huang, Q. Xi, R.-Q. Yu, J.-H. Jiang, and X. Chu, "A novel graphene oxide based fluorescent nanosensing strategy with hybridization chain reaction signal amplification for highly sensitive biothiol detection," Chemical Communications, vol. 50, no. 80, pp. 11879-11882, 2014.

[24] Y. Wang, L. Jiang, Q. Leng, Y. Wu, X. He, and K. Wang, "Electrochemical sensor for glutathione detection based on mercury ion triggered hybridization chain reaction signal amplification," Biosensors and Bioelectronics, vol. 77, no. 65, pp. 914-920, 2016.

[25] J. Sun, W. Jiang, J. Zhu, W. Li, and L. Wang, "Label-free fluorescence dual-amplified detection of adenosine based on exonuclease III-assisted DNA cycling and hybridization chain reaction," Biosensors and Bioelectronics, vol. 70, pp. 15-20, 2015.

[26] J. Huang, X. Gao, J. Jia, J.-K. Kim, and Z. Li, "Graphene oxidebased amplified fluorescent biosensor for $\mathrm{Hg} 2+$ detection through hybridization chain reactions," Analytical Chemistry, vol. 86, no. 6, pp. 3209-3215, 2014.
[27] S. Tang, P. Tong, M. Wang, J. Chen, G. Li, and L. Zhang, “A novel colorimetric sensor for $\mathrm{Hg} 2+$ based on hybridization chain reaction and silver nanowire amplification," Chemical Communications, vol. 51, no. 81, pp. 15043-15046, 2015.

[28] G. Zhou, M. Lin, P. Song et al., "Multivalent capture and detection of cancer cells with DNA nanostructured biosensors and multibranched hybridization chain reaction amplification," Analytical Chemistry, vol. 86, no. 15, pp. 7843-7848, 2014.

[29] Y. Zhang, Z. Chen, Y. Tao, Z. Wang, J. Ren, and X. Qu, "Hybridization chain reaction engineered dsDNA for $\mathrm{Cu}$ metallization: an enzyme-free platform for amplified detection of cancer cells and microRNAs," Chemical Communications, vol. 51, no. 57, pp. 11496-11499, 2015.

[30] T. Masuda T and P. D. Goldsmith, "World soybean production: area harvested, yield, and long-term projections," International Food and Agribusiness Management Review, vol. 12, no. 12, pp. 233-236, 2009.

[31] T. Sayama, E. Ono, K. Takagi et al., “The Sg-1 glycosyltransferase locus regulates structural diversity of triterpenoid saponins of soybean," The Plant Cell, vol. 24, no. 5, pp. 2123-2138, 2012. 